\title{
Sacrocolpopexy may cause difficult defecation by inhibiting the external opening out mechanism
}

\author{
Peter Petros $\cdot$ Michael Swash
}

Received: 13 August 2010 / Accepted: 18 September 2010 /Published online: 22 October 2010

(C) The International Urogynecological Association 2010

\section{Dear Editor,}

We congratulate Forsgren et al. [1] on an important study which demonstrated an increased incidence of evacuation disorders ("constipation") in patients who had undergone abdominal sacrocolpopexy. We would like to comment only on one aspect of the discussion, causation. In our 2008 Musculoelastic Theory of Anorectal Function and Dysfunction [2], we hypothesised that the mechanism for defecation involved backward stretching of the posterior rectal wall by a downward muscle force activated by contraction of the conjoint longitudinal muscle of the anus (LMA), a striated muscle. The LMA takes fibres from the pubococcygeus and puborectalis muscles and inserts into the external anal sphincter [3, 4]. It effectively contracts against the uterosacral ligament (USL, Fig. 1). With radiopaque dye inserted into the bladder, rectum, and levator plate muscles, we were able to confirm this action [5] using video x-rays. Opening out the faecal outflow tract by such an external mechanism vastly decreases the intraanal resistance, and allows easy passage of the faecal bolus. As the resistance varies inversely with the 4th power of the radius (Poisseuille's law), a sufficiently tight sacrocolpopexy in the position of USL (Fig. 1) will prevent the downward movement so essential to this opening out mechanism. The contracting rectum has to empty against a much higher intra-anal resistance, causing a functional obstruction, with symptoms thereof.

\section{P. Petros $(\bowtie)$}

University of Western Australia,

Perth, WA, Australia

e-mail: kvinno@highway1.com.au

\section{Swash}

Department of Neurology, The Royal London Hospital, London, UK

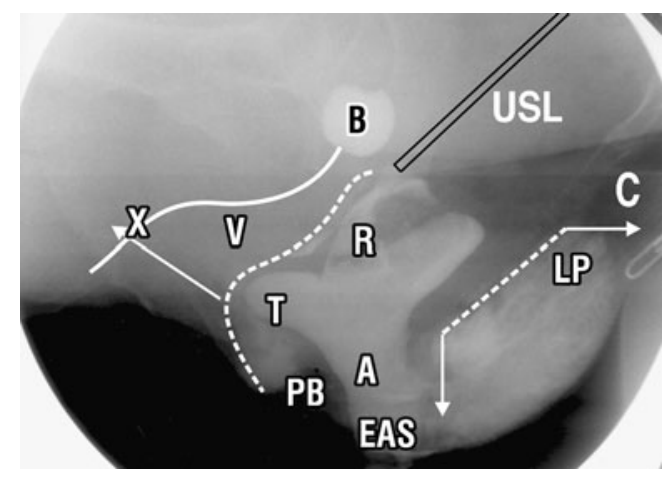

Fig. 1 Defaecation-Arrows denote directional movement of the organs consistent with stretching by muscle forces. Forward stretching of distal vagina $(V)$; backward stretching of proximal vagina, bladder $(B)$ and rectum $(R)$; downward angulation of levator plate $(L P)$ apparently against the uterosacral ligament (USL); marked widening of the anal canal $(A)$; bulge at $T$ consistent with anchoring by the deep transversus perinei part of the perineal body $(P B)$. EAS position of external anal sphincter

\section{References}

1. Forsgren C, Zetterström J, Zhang A, Iliadou A, Lopez A, Altman D (2010) Anal incontinence and bowel dysfunction after sacrocolpopexy for vaginal vault prolapse. Int Urogynecol J 21:1079-1084. doi:10.1007/s00192-010-1167-4

2. Petros PE, Swash M (2008) The musculoelastic theory of anorectal function and dysfunction. J Pelviperineology 27:89-93

3. Courtney H (1950) Anatomy of the pelvic diaphragm and anorectal musculature as related to sphincter preservation in ano-rectal surgery. Am J Surg 79:155-173

4. Macchi V, Porzionato A, Stecco C, Benettazzo F, Stecco A, Parenti A, Dodi G, De Caro R (2007) Histo-topographic study of the longitudinal anal muscle. Pelviperineology 26:30-32

5. Petros PE, Swash M (2008) Directional muscle forces activate anorectal continence and defecation in the female. J Pelviperineology 27:94-97 